\title{
Viral haemorrhagic fevers in South Africa
}

\author{
G A Richards, ${ }^{1} \mathrm{MB} B C h, \mathrm{PhD}, \mathrm{FRCP} ; \mathbf{J}$ Weyer, ${ }^{2} \mathrm{PhD} ; \mathrm{L}$ H Blumberg, ${ }^{3} \mathrm{MB}$ BCh, MMed (Micro), DTM\&H, DOH, DCH \\ ${ }^{1}$ Division of Critical Care, Faculty of Health Sciences, University of the Witwatersrand and Charlotte Maxeke Johannesburg Academic \\ Hospital, Johannesburg, South Africa \\ ${ }^{2}$ Centre for Emerging and Zoonotic Diseases, National Institute for Communicable Diseases, Sandringham, Johannesburg, South Africa \\ ${ }^{3}$ Division for Public Health, Surveillance and Response, National Institute for Communicable Diseases, Sandringham, Johannesburg, \\ South Africa
}

Corresponding author: G A Richards (guy.richards@wits.ac.za)

Viral haemorrhagic fevers (VHFs) include a diverse array of diseases caused by a broad range of viruses transmitted from various animal hosts and originating from almost all the continents in the world. These are potentially fatal and highly transmissible diseases without specific treatments or prophylactic vaccines. As has been demonstrated during the Ebola virus disease outbreak in West Africa, the consequences of VHFs are not limited to specific countries - they may become epidemic, and may have considerable economic impact and disrupt local public health and social service structures. Intensive public health intervention is necessary to contain these diseases. Here we provide a concise overview of the VHFs that are of current public health importance to South Africa.

S Afr Med J 2015;105(9):748-751. DOI:10.7196/SAMJnew.8330

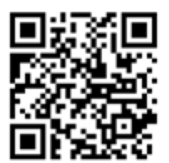

Viral haemorrhagic fevers (VHFs) are caused by infection with one of a number of zoonotic RNA viruses. Although the aetiology of the infections may differ, the clinical presentation can be remarkably similar. ${ }^{[1]}$ Patients typically experience nonspecific symptoms (especially early during the acute phase of illness) including fever of abrupt onset, headache, myalgia, lumbar pain, nausea, vomiting and diarrhoea. Progression to multisystem involvement is typically fairly rapid. Laboratory features of VHF include leucopenia, thrombocytopenia and elevated transaminases, while coagulation profiles become progressively abnormal and overt haemorrhagic features (ecchymoses, epistaxis, gingival bleeding, melaena, haematuria, etc.) may supervene from about day 5 after the onset of symptoms, or even earlier. Contrary to the name given to these conditions, haemorrhage is not a constant feature, as evidenced by the minority of patients who presented with overt haemorrhage during the current Ebola virus disease (EVD) outbreak. ${ }^{[2]}$ A petechial or maculopapular rash may also appear from day 3 to 10 , the exact timing of which varies with the virus concerned but is also related to the patient's response to the infection. There are few or no specific treatments available, as antivirals and preventive and therapeutic vaccines remain in the developmental phase. For this reason, given the extremely high mortality rates and the highly infectious nature of VHFs (infectious doses are as low as one viral particle for some), the haemorrhagic fever (HF)-causing viruses have to be handled and stored in the highest biosafety- and security-level laboratory conditions, and patient management must adhere to stringent isolation and barrier nursing protocols. The appropriate use of adequate personal protective equipment (PPE) is critical in all instances. However, there is controversy regarding the type of PPE that should be used, as highlighted by the lack of consensus among role players in West Africa during the EVD outbreak. For example, the use of respirators (specifically N95 respirators) v. surgical masks is disputed, since most VHFs are not considered to be airborne. ${ }^{[3,4]}$ Nevertheless, because aerosolisation is frequent during disinfection procedures, it is recommended that respirators be worn and that healthcare workers be observed by infection control staff to reduce transmission that occurs from contact of the virus with the face or neck, most frequently during removal of PPE or on inadvertently touching the face.

In Africa, the HF viruses belong to one of three families, namely the Arenaviridae (Lassa and Lujo viruses), Bunyaviridae (CrimeanCongo haemorrhagic fever (CCHF) and Rift Valley fever (RVF) viruses) and Filoviridae (Ebola and Marburg viruses). In general these diseases are limited to specific areas, and outbreaks most often occur in fairly isolated and rural settings. However, as demonstrated during the current EVD outbreak, increasing interconnectedness and ease of travel render the occurrence of VHFs a possibility anywhere in the world. Although the risk of importation into South Africa (SA) is considered to be low, ${ }^{[5]}$ the fact that considerable travel occurs between the rest of Africa and Johannesburg in particular, and vice versa, cannot be ignored. The indirect effects of VHF outbreaks have been demonstrated clearly during the ongoing West African EVD outbreak. Countries around the globe have been preparing their ports, healthcare systems and laboratories to detect and manage such cases at great financial cost, while travel restrictions and economic activities in numerous African economies (not just those directly affected) have also suffered. ${ }^{[6]}$ Interestingly, this effect is disproportionate to the actual number of cases of EVD, which remains small compared with other formidable public health problems such as malaria, tuberculosis and HIV-AIDS.

The differential diagnosis of VHF is broad and may include many treatable infectious diseases, most notably malaria, bacteraemia (including meningococcaemia) and African tick bite fever, as well as non-infectious conditions such as haematological malignancies and heatstroke. The diagnostic approach must consider each possibility carefully, as delay in diagnosis increases the potential for mortality and transmission. As such, it is wise to maintain a high index of suspicion, especially for patients presenting with a compatible clinical syndrome and who have histories that indicate a risk of having contracted an HF-causing virus (such as travel to endemic regions or contact with animals, raw bushmeat, sick patients, etc.). The HF-causing viruses have a propensity to spread in the hospital setting, and delay in recognition may have dire effects. ${ }^{[1]} \mathrm{A}$ small number of nosocomial outbreaks have occurred in SA: Marburg virus disease (MVD) in Johannesburg in 1975, CCHF near Cape Town 
in 1984, EVD in Johannesburg in 1996, and the Lujo virus, a newly identified arenavirus, in Johannesburg in $2008^{[7-10]}$ (these are dealt with in detail in the 'Clinical Alert' article in this issue of $\left.S A M J^{[11]}\right)$.

Here we provide a concise account of VHFs, endemic and nonendemic, of perceived importance to SA.

\section{The bunyaviruses}

CCHF is one of the most widely distributed VHFs, and has been described from more than 30 countries worldwide. ${ }^{[12]}$ These include central, south-western and south-eastern Europe, the Middle East, Africa including SA, and more recently Malaysia. ${ }^{[12,13]}$ The virus is typically ubiquitous in cattle-farming areas and corresponds to the distribution of the Hyalomma tick, the primary source of transmission. However, transmission also occurs following contact with infected animal blood or tissues, the majority of such cases having involved people in the livestock industry, such as agricultural and slaughterhouse workers and veterinarians.

In SA a total of 199 laboratory-confirmed cases of CCHF have been reported from 1981 to 2014 (data source: National Institute for Communicable Diseases, SA). These have been concentrated in the semi-arid farming areas of the Free State and Northern Cape provinces, although some have been recorded from all nine provinces. Interestingly, human cases remain relatively rare in SA, despite remarkably high seroprevalence rates in cattle and other ruminants. ${ }^{[14,15]}$ Cases of nosocomial and laboratory transmission ${ }^{[8,16,17]}$ have been noted on four occasions (data source: National Institute for Communicable Diseases) (see 'Clinical Alert' ${ }^{[11]}$ ). An outbreak was reported in 1996 in which a total of 17 laboratory-confirmed cases occurred involving slaughterhouse workers following contact with infected ostriches. ${ }^{[18]}$

CCHF has a case fatality rate of $5-30 \%$, and the clinical features, which are similar to those described above, are divided into four phases: incubation, pre-haemorrhagic, haemorrhagic and convalescence. ${ }^{[1,20]}$ The incubation period is usually 1 - 5 days following tick bite and slightly longer following exposure to blood products. The pre-haemorrhagic phase is manifested by sudden onset of fever, muscle aches, back pain, headache, sore eyes and photophobia. As with all the VHFs there may be early sore throat, nausea, vomiting, diarrhoea, lymphadenopathy and abdominal pain with hepatomegaly, often followed by confusion and lethargy. Thereafter the haemorrhagic phase begins on day $3-6$ with a petechial rash, purpura, ecchymoses and gastrointestinal and urinary tract bleeding. We have found that the majority of these cases initially present with leucopenia, thrombocytopenia occurring later in the disease process. At that time there may be a prolonged prothrombin time and activated partial prothrombin time (aPTT), and fibrin degradation products and D-dimers may be present. Hepatitis occurs with elevated transaminases (alanine (ALT) and aspartate (AST) transaminases). The disease is characterised by a diffuse capillary leak with hypovolaemia and acute kidney injury, and a fatal outcome may often be predicted by a persistently low platelet count, elevation of the AST and ALT to $>200$ and $>150 \mathrm{IU} / \mathrm{L}$, respectively, and of the aPTT to $>60$ seconds, and a decrease in the fibrinogen level to $<110 \mathrm{mg} / \mathrm{dL}{ }^{[19]}$ Bleeding and profound thrombocytopenia was a common finding in the SA cases, whereas in Central Europe clinical disease is highly variable with many mild cases reported.

The diagnosis is made by virus-specific reverse transcriptionpolymerase chain reaction (RT-PCR) and is usually positive at the onset of symptoms, although in circumstances that are highly suggestive of the disease it should be repeated a few days later and barrier nursing continued. ${ }^{[11,21]}$ Seroconversion may be expected from day 5 onwards, although this may be delayed in severe CCHF and may be a useful marker of prognosis. ${ }^{[19]}$ Anti-CCHF antibodies may be measured by indirect immunofluorescence assays or enzymelinked immunofluorescence assays for IgG and IgM. ${ }^{[19,21]}$

Therapy for CCHF is primarily supportive, and although the therapeutic benefit of ribavirin has not been adequately supported by studies to date, it is nevertheless recommended that it be used early in the disease at a loading dose of $30 \mathrm{mg} / \mathrm{kg}$, then $15 \mathrm{mg} / \mathrm{kg}$ every 6 hours $(4 \times 1 \mathrm{~g})$ for 4 days, and then $7.5 \mathrm{mg} / \mathrm{kg}$ every 8 hours $(4 \times 0.5 \mathrm{~g})$ for 6 days. ${ }^{[22]}$ The argument against the use of ribavirin is based on its potential renal and hepatic toxicity and the anecdotal nature of data supporting its use. ${ }^{[23]}$ Prevention of infection is based on prevention of tick exposures and use of appropriate PPE prior to contact with blood and tissues of ruminants in endemic areas. No vaccines are available.

RVF is caused by the mosquito-borne phlebovirus, also belonging to the family Bunyaviridae. The virus is widely distributed in Africa, including SA, but has also been reported from Saudi Arabia (after its introduction in 2000) and Madagascar. ${ }^{[24,25]}$ The RVF virus has caused intermittent outbreaks in domestic and wildlife ruminant species and humans in SA. ${ }^{[26-29]}$ The most recent outbreak in this country over the 4-year period 2008 - 2011 concluded with 25 deaths among 302 laboratory-confirmed cases from all nine provinces (although most were from the Free State and Northern Cape). ${ }^{[28]}$ RVF virus infection is typically asymptomatic or mild, manifesting as a febrile, flu-like syndrome with headache, nausea, myalgia and arthralgia. In a small proportion of cases, complications including encephalitis and HF may occur. ${ }^{[29]}$ The latter manifest during the first week of illness and are accompanied by severe hepatic impairment. The fatality rate of the haemorrhagic form may be up to $50 \%$. As with other VHFs, raised liver transaminases and thrombocytopenia generally precede death. ${ }^{[29,30]}$

Clinical diagnosis should be supported by specific laboratory testing, which includes RT-PCR, detection of anti-RVF virus IgG and IgM antibodies and virus isolation. Currently there is no accepted therapy for RVF and management is supportive only. In vivo studies of the antiviral favipiravir in small laboratory animals have shown promise ${ }^{[31]}$ No vaccines are commercially available to offer protection against RVF virus infection in humans.

\section{The filoviruses}

The filoviruses, EVD and MVD viruses, are known to cause highly fatal HF in humans and non-human primates. ${ }^{[32]}$ To date five distinct viral species have been ascribed to the Ebolavirus genus, namely Zaire, Sudan, Taï Forest, Reston and Bundibudyo Ebola viruses. ${ }^{[33]}$ These viruses vary enormously in terms of our current understanding of their geographical spread and also in their virulence in humans. For example, Reston Ebola viruses are not known to cause overt illness in humans (despite causing fatal HF in Asian non-human primates) ${ }^{[34]}$ while Zaire Ebola viruses cause one of the most lethal infections known to mankind. The current West African outbreak is caused by a Zaire Ebola virus very similar to those that have caused previous outbreaks in the Democratic Republic of the Congo and Gabon. ${ }^{[35]}$

The natural ecology of Ebola viruses remains largely obscure. Evidence hints at a specific arboreal species of bat as the reservoir for the Zaire species, ${ }^{[36-38]}$ but the specific mechanism of transfer from bat to human or bat to other forest-dwelling animals is not known. However, various human outbreaks have however been traced to contact with bushmeat, including the slaughtering of chimpanzees and bats. ${ }^{[39,40]}$ The recent West African outbreak has been traced to a 2-year-old child in Guinea who may have had contact with bats while at play. ${ }^{[35,41]}$ Once the virus enters the human population, 
transmission is through direct contact with infected body fluids such as blood, faeces and vomitus. Owing to this mode of transmission, the virus has a propensity to spread in the hospital setting and between close contacts. More than 20 outbreaks of EVD have been reported since 1976. ${ }^{[42]}$ Before 2014, these occurred in isolated settings with the largest involving 425 laboratory-confirmed cases reported from Gulu, Uganda, in 2000 and 2001. ${ }^{[42]}$ By the end of March 2015, one year after the World Health Organization (WHO) declared an outbreak situation, the diseases had accounted for a total of 14646 laboratory-confirmed cases (and 24754 in total if suspected and probable cases are included) and more than 10000 deaths. ${ }^{[43]}$ During this period more than 800 healthcare workers have contracted the disease, with nearly 500 losing their lives. ${ }^{[4]}$ The scale of this outbreak has been exacerbated by poor socioeconomic conditions in the affected countries and an inadequate medical infrastructure that caused delays in the initial recognition of the disease and failure to respond timeously. ${ }^{[2]}$ Consequently intensive international support on all fronts was, and continues to be, required.

Marburg virus is thought to be more widely distributed than Ebola virus, but despite this there have been only 12 outbreaks between 1967 and 2014, ${ }^{[45]}$ four of which consisted of single cases without further spread. There have been a total of 466 laboratory-confirmed cases with 373 deaths (an average fatality rate of $80 \%$, range $23-100 \%$ ). ${ }^{[45]}$ The largest outbreak centered in Uige Province in Angola, with 252 laboratory-confirmed cases from 2004 to 2005 with a $90 \%$ case fatality rate. ${ }^{[46]}$ In six of the outbreaks, the epidemiological history implicated bats as the source of the infection and this was further reinforced by the finding of serological and molecular evidence of Marburg virus in the Egyptian fruit bat, Rousettus aegyptiacus. ${ }^{[47]}$

Clinically the signs and symptoms of EVD and MVD are not dissimilar to those of the other VHFs. ${ }^{[32,48-50]}$ There are three phases: initially fever, headache, and myalgia, followed by diarrhoea, vomiting and dehydration; thereafter, in the second week, there may be recovery or deterioration with collapse, neurological manifestations and bleeding that can lead to a fatal outcome.

Fatal nosocomial infection with EVD and MVD has been reported in SA. ${ }^{[7,9]}$ It is noteworthy that appropriate management limited the outbreaks to single secondary cases (see 'Clinical Alert'[11]). Management of both diseases is supportive, involving active resuscitation and haemodynamic support. The usefulness of hyperimmune serum is uncertain, but it has been approved by the WHO for EVD in the context of the West African outbreak and clinical trials of various antiviral therapies are underway at the time of writing. ${ }^{[51]}$ To date there are no licensed vaccines for the prevention of either EVD or MVD. ${ }^{[32,52,53]}$ However, the extent of the current outbreak has led to the WHO expediting the evaluation and clinical validation of developmental vaccines. Since February 2015, case numbers have decreased leading to concerns that there may be insufficient healthcare workers and other volunteers to support clinical trial efforts in the affected countries. ${ }^{[54]}$

\section{The arenaviruses}

Before 2008, Lassa virus was the only arenavirus known to cause HF in Africa. The affected countries include Sierra Leone, Guinea, Liberia and Nigeria, where up to 500000 cases are estimated to occur annually. ${ }^{[55,56]}$ In West Africa, seroprevalence in select populations ranges from $8-52 \%$ in Sierra Leone and $4-55 \%$ in Guinea to $21 \%$ in Nigeria. Like other arenaviruses, Lassa virus is rodent-borne with the multimammate rat (Mastomys natalensis) the primary reservoir and vector of the disease. Transmission to the human population is mainly through aerolised urine and faecal matter that is contaminated with the virus.
Lassa fever has a variable clinical presentation from asymptomatic or mild infection to severe fatal HF in $20 \%$ of cases. Other common features include rigors, muscle pain, sore throat with exudates, nausea, vomiting, and chest and abdominal pain. ${ }^{[56-57]}$ Haemorrhagic features may include bleeding from the gums and internal bleeding, although the latter has been reported in less than one-third of severe Lassa fever cases. ${ }^{[56]}$ As with other VHFs, in severe cases progression is rapid to include multisystem dysfunction following an incubation period of $3-21$ days. $^{[56]}$ A feature of fatal illness is impaired or delayed cellular immunity leading to fulminant viraemia and shock, associated with platelet and endothelial dysfunction. ${ }^{\left[{ }^{[6]}\right.}$ The virus is excreted in urine for 3 - 9 weeks following infection and in semen for 3 months. Sensorineural hearing deficit may be found in $29 \%$ of cases v. zero in febrile controls. ${ }^{[57]}$ Lymphocytopenia and a moderate thrombocytopenia occur and are maximal $10-11$ days after symptom onset. Diagnosis is as for other VHFs, confirmed by specific laboratory testing involving RT-PCR, serology and virus isolation. Previously convalescent serum was used in the treatment of patients, but currently, if available, intravenous ribavirin may reduce mortality by up to $90 \% .{ }^{[58]}$ No vaccines exist for the prevention of infection with Lassa fever virus.

In 2008, a highly fatal outbreak of HF in Johannesburg was attributed to a previously unknown arenavirus, dubbed the Lujo virus (i.e. Lusaka-Johannesburg virus) (see 'Clinical Alert' ${ }^{[11]}$ ). ${ }^{[10,59,60]}$ The Lujo virus appears to have a particularly aggressive course ${ }^{[59]}$ in that among the five reported cases there has been only one survivor. The incubation period is 9 - 13 days and is followed by fever, headache and myalgia, and thereafter by diarrhoea, pharyngitis and a morbiliform rash on the face and trunk, reported in three cases. Facial oedema also occurred in three patients, with marked pharyngeal ulceration in one. There appeared to be initial clinical improvement after hospital admission in three patients, followed by sudden, rapid deterioration in those who died. Bleeding was not a prominent feature in these cases. The sole survivor of the outbreak received treatment including intravenous ribavirin. ${ }^{[60]}$ All the patients had thrombocytopenia on admission (range $42-104 \times 10^{9} / \mathrm{L}$ ), and the transaminases were raised in all five at some point during the course of their illness. ${ }^{[60]}$

The diagnosis of Lassa or Lujo virus infections, as for other VHFs, is based on specific laboratory testing involving RT-PCR, serology and virus isolation.

\section{Conclusion}

It is predicted that VHFs will continue to emerge and re-emerge in the future. With the ease of global travel and increasing interconnectivity, the isolated African VHF outbreaks of the past have changed dramatically, and the risk of exporting these diseases to new locations is now well appreciated.

Although the risk of introduction of VHF cases is relatively low, Johannesburg remains the gateway to and from Africa. Vigilance and awareness of VHF are therefore necessary to ensure rapid clinical recognition and implementation of systems that allow for the rapid and accurate laboratory investigation and containment of potential outbreaks.

\footnotetext{
References

1. Ftika L, Maltezou HC. Viral haemorrhagic fevers in healthcare settings. J Hosp Infect 2013;83(3):185192. [http://dx.doi.org/10.1016/j.jhin.2012.10.013]

2. World Health Organization Ebola Response Team. Ebola virus disease in West Africa - the first 9 months of the epidemic and forward projections. N Engl J Med 2014;371(16):1481-1495. [http:// months of the epidemic and forward profor
dx.doi.org/ 10.1056/NEJMoa1411100]

3. Macintyre CR, Chughtai AA, Seale H, Richards GA, Davidson PM. Uncertainty, risk analysis and change for Ebola personal protective equipment guidelines. Int I Nurs Stud 2014;2(5):899-903. [http:// change for Ebola personal protective equipment guidelines. Int J Nurs Stud 2014;2(5):899-903. [http://
dx.doi.org/10.1016/j.ijnurstu.2014.12.001]

4. MacIntyre CR, Chughtai AA, Seale H, Richards GA, Davidson PM. Respiratory protection for healthcare workers treating Ebola virus disease (EVD): Are facemasks sufficient to meet occupational
} 
health and safety obligations? Int J Nurs Stud 2014;51(11):1421-1426. [http://dx.doi.org/10.1016/j. ijnurstu.2014.09.002]

5. Weyer J, Blumberg LH. Ebola virus disease in West Africa - South African perspectives. S Afr Med J 2014;104(11):754-755. [http://dx.doi.org/10.7196/SAMJ.9045]

6. Schar D, Daszak P. Ebola economics: The case for an upstream approach to disease emergence. EcoHealth 2015;11(4):451-452. [http://dx.doi.org/10.1007/s10393-015-1015-6]

7. Gear JS, Cassel GA, Gear AJ, et al. Outbreak of Marburg virus disease in Johannesburg. BMJ $1975 ; 4(5995): 489-493$.

8. Van Eeden PJ, Joubert JR, van de Wal BW. A nosocomial outbreak of Crimean-Congo haemorrhagic fever at Tygerberg Hospital: Part I. Clinical features. S Afr Med J 1985;68(10):711-717.

9. Richards GA, Murphy S, Jobson R, et al. Unexpected Ebola virus in a tertiary setting: Clinical and epidemiologic aspects. Crit Care Med 2000;28(1):240-244. [http://dx.doi.org/10.1097/00003246200001000-00041

10. Paweska JT, Sewlall NH, Ksiazek TG, et al. Nosocomial outbreak of novel arenavirus infection, southern Africa. Emerg Infect Dis 2009;15(10):1598-1602. [http://dx doi. org/10.3201/eid1510.090211]

11. Richards GA. Nososcomial transmission of viral haemorrhagic fever in South Africa. S Afr Med J 2015;105(9):709-712. [http://dx.doi.org/10.7196/SAMJnew.8168]

12. Burt FJ, Goedhals D. Crimean-Congo haemorrhagic fever virus, an emerging and re-emerging pathogen. In: Sing A, ed. Zoonoses - Infections Affecting Humans and Animals. Dordrecht: Springer, 2015:977-996. [http://dx.doi.org/10.1007/978-94-017-9457-2_39]

13. Lani R, Rahim NFM, Hassan $\mathrm{H}$, et al. First report on the seroprevalence of the Crimean-Congo haemorrhagic fever virus, a tick-borne virus, in Malaysiałs Orang Asli population. Eur Rev Med Pharmacol Sc 2015;19(3):461-466.

14. Burt FJ, Swanepoel R, Braack LEO. Enzyme-linked immunosorbent assays for the detection of antibody to Crimean-Congo haemorraghic fever virus in sera of livestock and wild vertebrates. Epidemiol Infect 1993;111(3):547-557. [http://dx.doi.org/10.1017/s0950268800057277]

15. Swanepoel R, Shephard AJ, Leman PA, Shephard SP, Miller GB. A common-source outbreak of Crimean-Congo haemorrhagic fever on a dairy farm. S Afr Med J 1985;68(9):635-637.

16. Shepherd AJ, Swanepoel R, Shepherd SP, Leman PA, Blackburn NK, Hallett AF. A nosocomial outbreak of Crimean-Congo haemorrhagic fever at Tygerberg Hospital. S Afr Med J 1985;68(10):733-736.

17. National Institute for Virology. Annual Report 1985. Johannesburg: Department of National Health and Population Development, 1986:24.

18. National Institute for Virology. Annual Report 1996. Johannesburg: Department of Health, 1997:14.

19. Swanepoel R, Gill DE, Shephard AJ, Leman PA, Mynhardt JH, Harvey S. The clinical pathology o Crimean-Congo hemorrhagic fever. Rev Infect Dis 1989;11(Suppl 4):S794-S800. [http://dx.doi. org/10.1093/clinids/11.supplement_4.s794]

20. Ergönül Ö. Crimean-Congo haemorrhagic fever. Lancet 2006;6(4):203-214. [http://dx.doi.org/10.1016 s1473-3099(06)70435-2]

21. Tezer H, Polat M. Diagnosis of Crimean-Congo haemorrhagic fever. Exp Rev Anti Infect The 2015;13(15):555-556. [http://dx.doi.org/10.1586/14787210.2015.1021782]

22. Ergönül Ö. Evidence supports ribavirin use in Crimean-Congo hemorrhagic fever. Int J Infect Dis 2014;29:296. [http://dx.doi.org/10.1016/j.ijid.2014.08.016]

3. Ceylan B, Turhan V. The efficacy of ribavirin in Crimean-Congo hemorrhagic fever - randomized trials are urgently needed. Int J Infect Dis 2014;29:297-298. [http://dx.doi.org/10.1016/j.ijid.2014.08.015]

24. Clements ACA, Pfeiffer DU, Martin V, Otte MJ. A Rift Valley fever atlas for Africa. Prev Vet Med 2007;82(1-2):72-82. [http://dx.doi.org/10.1016/j.prevetmed.2007.05.006]

25. Pepin M, Bouloy M, Bird BH, Kemp A, Paweska J. Rift Valley fever virus (Bunyaviridae: Phlebovirus): An update on pathogenesis, molecular epidemiology, vectors, diagnostics and prevention. Vet Res 2010;41(6):61. [http://dx.doi.org/10.1051/vetres/2010033]

26. Swanepoel R, Coetzer JAW. Rift Valley fever. In: Coetzer JAW, Tustin RC, eds. Infectious Diseases of L Swanepoel R, Coetzer JAW. Rift Valley fever. In: Coetzer JAW, Tustin RC,
Livestock. 2nd ed. Cape Town: Oxford University Press, 2005:1037-1070.

27. Archer VN, Weyer J, Paweska J, et al. Outbreak of Rift Valley fever affecting veterinarians and farmers in South Africa, 2008. S Afr Med J 2011;101(4):263-266

28. Archer BN, Thomas J, Weyer J, et al. Epidemiologic investigations into outbreaks of Rift Valley fever in humans, South Africa, 2008-2011. Emerg Infect Dis 2013;19(12):1918-1924. [http://dx.doi. org/10.3201/eid1912.121527]

29. Paweska JT. Rift Valley fever. In: Ergönül Ö, Can F, Akova M, Madoff L, eds. Emerging Infectious Diseases: Clinical Case Studies. London: Academic Press,2014:73-93.

30. Al Hazmi M, Ayooka EA, Abdurahman M, et al. Epidemic Rift Valley fever in Saudi Arabia: A clinical study of severe illness in humans. Clin Infect Dis 2003;36(3):245-252. [http://dx.do org/10.1086/345671]

31. Scharton D, Bailey KW, Vest Z, et al. Favipiravir (T-705) protects against peracute Rift Valley feve virus infection and reduces delayed-onset neurological diseases observed with ribavirin treatment. Antiviral Res 2014;104(April):84-92. [http://dx.doi.org/ 10.1016/j.antiviral.2014.01.016]
32. Rougeron V, Feldmann H, Grard G, et al. Ebola and Marburg haemorrhagic fever. J Clin Virol 2015;64:111-119. [http://dx.doi.org/10.1016/.j.jcv.2015.01.014]

33. Barrette RW, Xu L, Rowland JM, McIntosh MT. Current perspectives on the phylogeny of Filoviridae. Infect Genet Evol 2011;11(7):1514-1519. [http://dx.doi.org/ 10.1016/j.meegid.2011.06.017]

34. Morikawa S, Saijo M, Kurane I. Current knowledge on lower virulence of Reston Ebola virus (a review). Comp Immunol Microbiol Infect Dis 2007;30(5-6):391-398. [http://dx.doi.org/10.1016/j. imid.2007.05.005

35. Baize S, Pannetier D, Oestereich L, et al. Emergence of Zaire Ebola virus disease in Guinea - preliminary report. N Engl J Med 2014;371(15):1418-1428. [http://dx.doi.org/ 10.1056/NEJMoa1404505]

6. Pourrut X, Kumulungui B, Wittmann T, et al. The natural history of Ebola virus in Africa. Microbes Infect 2005;7(7-8):1005-1014. http://dx.doi.org/10.1016/j.micinf.2005.04.006]

37. Groseth A, Feldmann H, Strong JE. The ecology of Ebola viruses. Trends Microbiol 2007;15(9):408416. [http://dx.doi.org/10.1016/j.tim.2007.08.001]

38. Olival KJ, Hayman DT. Filoviruses in bats: Current knowledge and future directions. Viruses 2014;6(4):1759-1788. [http://dx.doi.org/10.3390/v6041759]

39. World Health Organization. Outbreak(s) of Ebola haemorrhagic fever, Congo and Gabon, October 2001-July 2002. Wkly Epidemiol Rec 2003;78(26):223-225.

40. World Health Organization. WHO declares end of Ebola outbreak in the Democratic Republic of Congo. http://www.who.int/mediacentre/news/statements/2014/drc-ends-ebola/en/ (accessed 17 December 2014).

41. Saéz M, Weiss S, Nowak K, et al. Investigating the zoonotic origin of the West African Ebola epidemic. EMBO Mol Med 2014;7(1):17-23. [http://dx.doi.org/10.15252/emmm.201404792]

42. Centers for Disease Control and Prevention. Outbreaks chronology: Ebola virus disease. http://www. cdc.gov/vhf/ebola/outbreaks/history/chronology.html (accessed 23 March 2015).

43. Centers for Disease Control and Prevention. 2014 Ebola outbreak in West Africa - case counts. http:// www.cdc.gov/vhf/ebola/outbreaks/2014-west-africa/case-counts.html (accessed 23 March 2015).

44. World Health Organization. Ebola situation report - 18 March 2015. http://apps.who.int/ebola/ current-situation/ebola-situation-report-18-march-2015 (accessed 23 March 2015).

45. Centers for Disease Control and Prevention. Chronology of Marburg hemorrhagic fever outbreaks. http://www.cdc.gov/vhf/marburg/resources/outbreak-table.html (accessed 23 March 2015).

46. Centers for Disease Control and Prevention. Outbreak of Marburg virus hemorrhagic fever - Angola. 1 October 2004-29 March 2005. MMWR Morb Mortal Wkly Rep 2005;54(12):308-309.

47. Towner JS, Pourrut X, Albariño CG, et al. Marburg virus infection detected in a common African bat. PLoS One 2007;8:e764. [http://dx.doi.org/10.1371/journal.pone.0000764]

48. Hartman AL, Towner JS, Nichol ST. Ebola and Marburg hemorrhagic fever. Clin Lab Med 2010;30(1):161-177. [http://dx.doi.org/10.1016/j.cll.2009.12.001]

49. Beeching NJ, Fenech M, Houlihan C. Ebola virus disease. BMJ 2014;349:g7348. [http://dx.doi. org/10.1136/bmj.g7348]

50. Formenty P. Ebola virus disease. In: Ergönül O, Can F, Akova M, Madoff L, eds. Emerging Infectious Diseases, Clinical Case Studies. London: Academic Press, 2014:121-134.

51. Gulland A. First Ebola treatment is approved by WHO. BMJ 2014;349:g5539. [http://dx.doi. org/10.1136/bmj.g5539]

52. Reed DS, Mohamadzadeh M. Status and challenges of filovirus vaccines. Vaccine 2007;25(11):19231934. [http://dx.doi.org/10.1016/j.vaccine.2006.11.037]

53. Sridhar S. Ebola and Marburg vaccines for Africa: One step closer. Lancet 2014;385(9977):1491-1493. [http://dx.doi.org/10.1016/S0140-6736(14)62445-4]

54. MacKenzie D. Ebola’s retreat thwarts drug and vaccines trails. New Sci 2015;225(3008):14. [http:// dx.doi.org/10.1016/S0262-4079(15)60292-5]

55. Ogbu O, Ajuluchukwu E, Uneke CJ. Lassa fever in West African sub-region: An overview. J Vector Born Dis 2007;44(1):1-11.

56. Richmond JK, Baglole DJ. Clinical Review. Lassa fever: Epidemiology, clinical features, and social consequences. BMJ 2003;327:1271. [http://dx.doi.org/10.1136/bmj.327.7426.1271]

57. McCormick JB, King IJ, Webb PA, et al. A case-control study of the clinical diagnosis and course of Lassa fever. J Infect Dis 1987;155(3):445-455.

58. McCormick JB, King IJ, Webb PA, et al. Lassa fever: Effective therapy with ribavirin. N Engl J Med 1986;314(1):20-26.

59. Paweska JT, Jansen van Vuren P, Weyer J. Lujo hemorhagic fever. In: Singh SK, Ruzek D, eds. Viral Haemorrhagic Fevers. 1st ed. Boca Raton, FL: CRC Press, 2013:287-305.

60. Sewlall NH, Richards GA, Duse A, et al. Clinical features and patient management of Lujo haemorrhagic fever. PLoS Negl Trop Dis 2014;8(11):e3233. [http://dx.doi.org/10.1371/journal.pntd.0003233]

Accepted 13 July 2015. 